\title{
Analysing information literacy practices at selected academic libraries in Zimbabwe
}

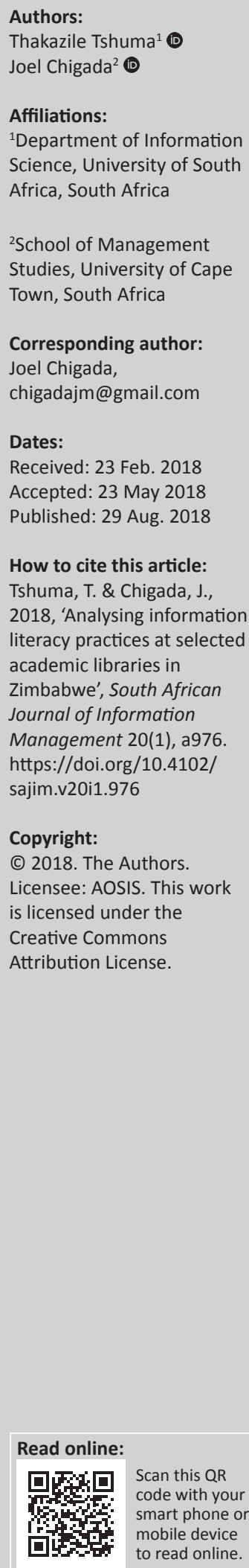

Background: Information literacy (IL) skills are significant in the knowledge and information economy because the IL skills allow information users to cope with the challenges of an evolving and complex information landscape. IL is one of the most important aspects in academic libraries because it equips university communities with the skills of finding, locating and using information effectively and efficiently.

Objectives: The study focused on evaluating the IL programmes and practices, as well as the challenges of implementing IL at selected academic libraries in Zimbabwe. The objective was to establish the existing policies and skills required by institutions of higher learning to implement and teach IL.

Method: Qualitative data collected using face-to-face interviews and focus group interviews were analysed with the assistance of Qualitative Data Analysis Software (Atlas. ti version 8). Participants of the study included the library directors and assistant librarians with regard to IL modules and the Zimbabwe Universities Library Consortium policy documents.

Results: The results revealed that all librarians understood the importance of IL in academic libraries; however, there were no IL policies and skills in existence, either at national, consortium or institutional levels. The study revealed that Zimbabwean academic libraries used different and incoherent methods in implementing and teaching IL and that IL initiatives were confronted with a myriad of challenges.

Conclusion: The study concluded that academic libraries should have IL policies in place which aid in the implementation and teaching of IL in Zimbabwean academic libraries, as well as guide all the consortium members especially on collaboration issues, teaching aspects, as well as the recognition of IL by university stakeholders other than the librarians.

\section{Introduction and background to the study}

Information literacy (IL) started as bibliographic instruction or user education which did not cover some aspects of technology. This was confirmed by the Institute of Standing Conference of Eastern, Central and Southern African Library (SCECSAL) Report (2010:25), which indicates that IL started as an unscheduled bibliographic instruction at the University of Botswana and by considering the technological changes, it was then converted to IL. It was changed to IL to incorporate the 21st century technology into library operations and improve the services in academic libraries. The Association of College and Research Libraries (ACRL, 2014) indicates that many institutions of higher education in the world over-accepted IL and embraced it after analysing its benefits of IL. Thus, this helped the interested institutions in developing, assessing and improving IL programmes.

Developed countries embraced IL skills at the end of the 19th century and at the beginning of the 20th century (Saracevic 2014), whereas in Africa, many students at various levels of education are still short of skills to explore and navigate different information resources (Baro \& Fyneman 2009). Most of the African countries, including Zimbabwe, are beginning to embrace IL as a worldwide trend in higher education libraries. The SCECSAL Report (Institute of Development Studies and Information Training and Outreach Centre for Africa 2010) report declares that a growing number of institutions developed IL because of its impact on students' academic output. Librarians and information professionals around the world believe that the teaching of an IL programme enhances the learning experience of students and it becomes a mechanism for lifelong learning. This is supported by ACRL (2000), which indicates that 'IL forms the basis of lifelong learning and enables learners to master content and extend their investigations to become more self-directed'. 
The SCECSAL Report (Institute of Development Studies and Information Training and Outreach Centre for Africa 2010) and Mugwisi (2015) highlighted that the IL programme was adopted by Zimbabwe library professionals in the early 2000s. However, there is very little that is known about the IL programme being part of the curriculum, despite the fact that most academic librarians were trained and equipped through the International Network for the Availability of Scientific Publications (INASP) training. Considering that academic librarians understand the concept of IL, there is a need to evaluate and explore the strategies, processes and the models of IL delivery in academic libraries in Zimbabwe.

\section{Problem statement}

Librarians, academics at universities and society understand the importance of IL; however, little has been done to develop and incorporate IL curricula in academic programmes. Preliminary research shows that Zimbabwean academic libraries view IL in different ways, as some have formalised and integrated IL into the university programmes, while some universities still offer IL on a voluntary basis. IL skills are significant in the knowledge economy because the skills allow information users to cope with the challenges of an evolving and complex information landscape by giving them the skills to know when and where to locate information effectively and efficiently (ACRL 2014). The absence of formalised IL at university level leads to lack of succession in the information society as well as impedes the acquisition and sharing of information. In addition, the absence of IL impedes users from coping with the complex information landscape.

Lack of IL may also lead to fewer lifelong learners in the society. The African Economist magazine (2013) states that the only way to investigate the literacy rate concept and explore innovative strategies is to sustain the country's literacy levels through adopting IL programmes into the curriculum. Therefore, universities are likely not to meet some of their objectives without IL being incorporated into the curriculum, whereas students may not have the IL skills needed to continue developing themselves after the academic life. The SCECSAL (2010) report showed that the IL skills programme was well received and embraced by many library professionals in Zimbabwe in the early 2000s, as they regarded it as an imperative aspect of academic achievements. However, there is very little that is known about the IL programme being part of the curriculum, despite the fact that most academic librarians were trained and equipped through INASP training programmes. With the absence of IL programmes in place, students, academics and other information users might not execute or make informed decisions timeously. Information users might fail to search or use search tools and engines to get relevant information.

\section{Theoretical framework}

Theoretical framework helped the researchers to identify certain models that aid librarians in implementing and teaching IL. The two theoretical frameworks were the Interview, Design, Embed and Assess (IDEA) and Analysis,
Design, Development, Implementation, and Evaluation (ADDIE) models. These models influence the delivery of IL in academic libraries through training, planning, and the presentation of IL programmes (Summey \& Valenti 2013). The models are both faculty- and librarian-based which enable librarians to adopt them with ease. Analysis, Design, Development, Implementation, Evaluation and IDEA models guide instruction to librarians in designing and developing an IL module for students.

\section{Interview, Design, Embed and Assess model}

Summey and Valenti (2013) state that the IDEA model is made up of four phases, namely: interview, design, embed and assess. During the first phase, students are interviewed to identify any skills among the students. The second stage assists the instructor to design the module according to the needs of the students. The third phase allows the IL programme to be embedded into other programmes or courses available. Thereafter, assessment is done to find out if the programme yielded positive results or not.

\section{Analysis, Design, Development, Implementation and Evaluation model}

Tompkins et al. (2014:140) describe ADDIE model as an instructional design model that is useful in evaluating and integrating new technologies into a library instruction programme. The model addresses the faculty and the librarian perspective in the process of designing a module. The analysis, Design, Development, Implementation, and Evaluation model provides a powerful guideline to librarians in creating IL modules, revising the existing IL modules and incorporating new technologies into the IL programme. The model comprises five phases, namely: analyse, design, develop, implement and evaluate. The first stage is the analytic stage where the instructional librarian defines the IL content. It is followed by the design phase, specifying how IL will be delivered to students. The third stage is development, focusing on developing an IL module and the materials needed for the programme such as slides. The fourth stage is implementation when the librarian installs the instruction product, and lastly the evaluation stage when the librarian determines the impact of the course.

\section{The value of the models in the study}

The IDEA and ADDIE model underline the procedure and the strategy of implementing IL in academic libraries (Mullins 2014 \& 2016). Concerning the implementation of an IL programme, these cannot be randomly done, as instructors believe, the model clearly highlights the stages of implementing the IL programme in an academic set up. The models help the study to define the importance of following the implementation procedure in order to fully implement IL. The study focuses on IL teaching methods and the two models also address 
these, helping one to identify the best method of teaching, IL. The two models clearly show the need for collaboration, as well as engaging the users before the IL programme implementation. The two models articulate the stages necessary in implementing and teaching IL in academic libraries. Generally, several authors such as Hart and Davids (2010), Maitaouthong, Tuamsuk and Tachamanee (2012) and Lwehabura and Stillwell (2008) highlight issues of collaboration while the two models specifically indicate whom to collaborate with and show the collaboration processes. However, the two models do not address the issues of integrating IL into the curriculum, which is one of the major aims of the study. In addition, the models do not show ways of dealing with challenges faced during the implementation and teaching of IL programme in academic libraries.

In a Zimbabwean context, the ADDIE and IDEA models could be used in evaluating and implementing an IL skills programme. The students need the help of librarians to acquire skills of accessing information from the library. The same applies to the librarians, as they need the skills in designing, developing and delivering through the application of the two models (Mullins 2014 \& 2016). The major goal of these models is to help librarians and faculty understand their students as well as their research needs. Goodman (2009) in Summey and Valenti (2013) highlights several steps to be utilised by librarians to systematically create library instructions, which are the following: assess the instructional needs and situation; determine learning objectives; develop an instructional plan and activities; deliver the instruction and measure the outcomes against the learning objectives. Mullins (2014:340) indicates that literature shows an increasing contemporary use of the two models in higher education institutions.

\section{Literature review}

The literature review helped the researchers to establish what other researchers got in the area of IL. Different scholars defined IL in different ways; however, for the purpose of this study the researchers adopted the ACRL definition which is the most widely used definition (ACRL2014). Information literacy has been identified as an important aspect in the education cycle as it develops individuals into lifelong learners. Hart and Davids (2010) and the SCECSAL Report (Institute of Development Studies and Information Training and Outreach Centre for Africa 2010) state that IL is a priority for university libraries and a key to raising the institutional standards by improving the quality of research, teaching and learning. The United Nations Education \& Scientific Organisation (UNESCO) (The Society for the Advancement of Library and Information Science (SALIS), in collaboration with UNESCO and BS Abdur Rahman Crescent Engineering College (2009), relates IL skills to capacity building, indicating that it assists to understand, participate actively in and benefit fully from the emerging knowledge societies. Generally, IL has been identified as a tool that mitigates challenges of data smog as well as bridges the digital divide.

\section{Importance of information literacy skills programme at universities}

As information online resources are enormously increasing, students need to be able to navigate and access information through these platforms with confidence. There is growing evidence that reliance on Internet sources negatively affects the quality of students' writing (Radia \& Stapleton 2008:9), thereby emphasising the importance of IL. The American Library Association (ALA) (2000:4) revealed that IL augments students' competency in evaluating, managing and using IL skills and it is now considered by several regional and discipline-based accredited associations as a key outcome for college students. Hodgens, Sandal and Evans (2012) highlighted that, although students have confidence in the skills they have, it is always crucial to grant them IL skills. Chipeta (2010) corresponds that IL is important as it offers the 21st-century skills, which enable students to succeed in the information economy as it is needed as employability skills. The importance of acquiring IL skills improves the opportunities for students' selfdirected learning as they become engaged in using a wide variety of information sources to expand their knowledge and sharpen their critical thinking skills for further selfdirected learning (ACRL 2000:3). As students complete their studies, IL increases their chances of performing better in the society. United Nations Education \& Scientific Organisation (2009) relates IL skills to capacity building, indicating that it assists to understand, participate actively in and benefit fully from the emerging knowledge societies. Lifelong learning is essential for survival in a changing world with evolving technology and enormous information reservoirs. United Nations Education and Scientific Organisation (2009) concurs that IL provides the foundation for lifelong learning, which is increasingly viewed as a fundamental human right which aids in communication, critical thinking and problem-solving.

\section{Information literacy in academic libraries}

IL equips users with appropriate searching and researching skills at institutions of higher learning as they rely less on their lecturers. Information literacy equips students with skills that enable them to face the 21st-century demands and challenges that surround the information economy. Chipeta (2010) opines that academic libraries have become teaching libraries as they are actively involved in all aspects of higher education, teaching, research and community service. From the literature reviewed, there is a need for an IL policy to successfully implement an IL programme (Mugwisi 2015). Academic libraries from countries such as South Africa, Tanzania and Kenya have witnessed that lack of an IL policy becomes a hindrance to the implementation of an IL programme. Other challenges mentioned were the poor infrastructure, inadequate resources (human resources and time) and lack of collaboration efforts by other university stakeholders (Hepworth \& Wema 2006). 


\section{Information literacy policy}

An IL policy, in general perspective, is there to guide the implementation, teaching and designing of the content for IL programmes in institutions. This is also noted by Fitzpatrick and Meulemans (2011:142) as indicated in Kimani (2014:39), who states that standards provide a framework for academic librarians in developing, delivering and assessing instructions on finding and using information in the higher education setting, both within major and in general education courses. The ALA (2000:5) clearly states that Information Literacy Competency Standards for Higher Education provides a framework for assessing the information literate individual, thus enabling institutions to assess their students and researchers on IL. Thus, ACRL (2014) in the Framework for Information Literacy for Higher Education laid a foundation that could be adopted by institutions in formulating their own IL policies.

The International Association of University Libraries (IATUL) Report (2015:12) states that countries such as Australia have developed the IL and literacy policy, which compels academic library staff and academics to integrate IL in the curricula. The Society of College, National and University Libraries (SCONUL) seven pillars of IL policy has been developed to address IL needs in academic libraries. Larger library associations have developed national standards that can be adopted and implemented by academic libraries. It is acknowledged that the Zimbabwe University Libraries Consortium (ZULC) is a signatory to SCONUL, IATUL; however, there is dearth of information, suggesting the existence of IL policies in place. The existence of IL policies should extend beyond the needs of students in higher education, but to include schools and public library involvement in lifelong learning (IATUL, Report 2015:7).

\section{Methodology}

The researchers followed the interpretive way to explore IL practices in academic libraries in Zimbabwe. This enabled the researchers to interpret data from the participant's view (Hennink, Hutter \& Bailey 2011), as well as getting a deeper understanding on IL among Zimbabwean academic libraries.

Qualitative data were collected from participants through face-to-face and focus group interviews. These approaches enabled engagements with participants while learning more about the phenomenon from the participants' views and experiences (Creswell 2009). Various data collection techniques and sources were used in this study, culminating in the triangulation of data at collection, analysis and interpretation. By triangulating, the trustworthiness and dependability of data were enhanced. Instead of using individual interviews only, the data were collected from a focus group for conformability purposes. Yin (2012) indicates that it is worth employing the concept of triangulating when one is to ask the same questions in different interviews or ask the same question from different sources of evidence.
A multiple case study as research design was used to help collect data from multiple sources, enabling the authors to concentrate more on the area of interest and look at it in detail, not seeking to generalise the results (Thomas 2011). The authors opted for an exploratory type of case study to understand attitudes and provide perceptions of participants during the research process. This helped authors to discover facts and reality on IL practices while gaining a better understanding and knowledge of IL programmes in Zimbabwe.

The authors used purposive sampling as a sampling strategy because it was influenced by the types of participants targeted in the study. Personal judgement enabled the authors to know who to include in the study (Rubin \& Babbie 2008:204), as individuals partaking in the decision making and the teaching of IL were targeted. Data collected were analysed through the use of Qualitative Data Analysis Software (Atlas ti. version 8). Roller and Lavrakas (2015:21) and Rubin and Babbie (2008:234) describe trustworthiness as an approach used to test the appropriateness and credibility of research findings.

\section{Research findings}

The study established that some institutions had IL modules in place, while others did not have. Participants could not provide an IL policy document for individual libraries; instead, the consortium had a standard document that guides the operations of all members of the consortium. Most of the faculty librarians seem not to be aware of an IL policy document. The study established that participants were not conversant with information practices in their institution, a clear indication that IL was not part of the curricula.

\section{Importance of information literacy}

The general response from participants was that IL:

- contributes to students' academic output,

- equips students and researchers with skills to carry out quality research,

- helps students use both print and e-resources,

- supports teaching and learning, and

- prepares students to be independent learners, as well as for lifelong learning purposes.

This is supported by Hart and Davids (2010) and SCECSAL Report (Institute of Development Studies and Information Training and Outreach Centre for Africa 2010) who stated that IL is a priority for university libraries and a key to raising the institutional standards by improving the quality of research, teaching and learning. This happens when students have the skills to find both print and e-sources as information resources, as well as finding the required information in a short space of time, thereby communicating that information effectively. This was also indicated by Tiemensma (2012) who highlights that electronic resources organise information in different ways, which then requires specific IL skills for users to access, locate and retrieve the needed information from electronic databases. This view is supported by UNESCO (The Society for the Advancement of 
Library and Information Science (SALIS), in collaboration with UNESCO and BS Abdur Rahman Crescent Engineering College (2009), which concurs that IL provides the foundation for lifelong learning which is increasingly viewed as a fundamental human right that aids in communication, critical thinking and problem-solving.

\section{Information literacy module content}

Both university librarians and faculty librarians indicated the following as the major areas of concern for IL: evaluation of information sources, referencing and citation, information sources, information access tools and theory of information retrieval. These were also suggested as the major topics for an IL by Baro (2011). In addition, participants were expected to share what they expect on the IL module in terms of content. Considering the technological changes as well as the background of students in institutions, there should be an IL module that ensures a consistent delivery of IL to library users. Most participants highlighted the same issues, although institutions differ in delivery methods.

\section{The role players in the development of an information literacy module}

Participants indicated a need for strong collaboration between the librarians and other university stakeholders. It was highlighted that the faculties had better knowledge relating to the needs of students and formulation of synopsis; therefore, collaboration of academics with librarians will help to produce concrete results. This is supported by several authors such as Cobus (2008) and Maitaouthong et al. (2012), who emphasised that teaching of an IL programme calls for cooperation between librarians and the educators. Lawal et al. (2010:53) confirm that librarian and faculty collaboration is a good strategy in making IL an integral part of the university curricula, although it tends to create conflict between librarians and faculty, especially with regards to issues of curriculum planning and design.

\section{Faculty librarians' training}

It was acknowledged that faculty librarians possessed diploma and degree qualifications and skills and were better equipped to deliver IL effectively. The need for further training was raised so as to impart relevant skills that address the challenges of the knowledge economy. In as much as the above-mentioned groups of people should be involved in the design and development of IL, the delivery should be in the hands of the librarians. This is in line with the views of Lau (2006) who testified that regardless of the size of a library and its resources, the library plays an important role in teaching an institutional IL programme, as well as through collaborating with academics to ensure effective IL training.

\section{Information literacy policy}

Both faculty librarians and the university librarians were asked if they were aware of any IL policy regarding the provision of IL. The results regarding this question did not yield much and this led to the researchers not proceeding with other questions related to this section. During the interviews with faculty librarians, they indicated unawareness of the IL policies available to the consortium members. On the other hand, the ZULC executive members indicated the availability of a standard ZULC document specifically for the consortium that covers all library services in general, not an IL policy. This is a weakness experienced by many academic libraries as Berkman (2016) discovered through Mader's (2016) findings, who is a visiting programme officer for information literacy. During an interview, Mader (2016) noted that institutions around the world have not done much in terms IL policy; instead, they all rely on the ACRL new IL framework. The researchers had access to the standard ZULC document, which pinpointed few issues concerning IL. Berkman (2016) further indicates a great need for national policies on IL, which is created and administered by the government.

It was established that selected Zimbabwean institutions do not have documented IL policies as individual institutions and at consortium level. The lack of an IL policy by the consortium emanates from the lack of recognition by the board monitoring quality standards of higher and tertiary education, which is the Zimbabwe Council of Higher Education (ZIMCHE). Respondents from the focus group agreed that an IL policy approved and enacted by the ZIMCHE going down to the consortium and then institutions may yield a successful implementation of IL in all Zimbabwean academic libraries. This was emphasised by Amunga (2011), Moyo and Mavodza (2015) and Tiemensma (2012), who confirmed that South African institutions achieved this goal through the use of such channels.

\section{Implementation and teaching strategies}

It is of importance for academic libraries to develop strategies for implementing IL programmes. Participants were asked if they practised any strategies in implementing IL and they were requested to highlight all the strategies they used. Participants shared different ways of implementing IL such as introducing IL as an accredited course, integrating IL with other courses, as a stand-alone programme and as part of orientation.

IL teaching methods differ with institutions and this was confirmed by Mugwisi (2015) in that Zimbabwean universities also vary in terms of IL programmes as some institutions teach IL as a stand-alone course while others consider it as a topic in related courses. The researchers through literature review identified a number of teaching methods and these were highlighted to participants during interviews. The participants were also asked about the teaching method they use in their institutions and what they will recommend to be the best teaching method. 
Some participants indicated that IL is taught on voluntary basis, although it is not recommended, especially in an academic library set up because some students will never get an opportunity or be exposed to the skills offered through an IL programme. During the interview discussion, participants indicated that in-class tutorial may be appropriate as handson practical will take place and this it will help students with different backgrounds to benefit as well. Other participants argued and indicated that a hybrid method is the best way of teaching IL as this will cover both in-class tutorials as well as online tutorials because it caters for all kinds of students.

Some indicated that IL has been integrated with other university programmes; therefore, every student enrolled with the institutions benefit from IL. For institutions that provide IL, it was pointed out that all is going well in terms of delivering IL because it is integrated into the curriculum and it is mandatory for every student to attend the lectures for that course. Participants confirmed that a hybrid method works well and that it is very effective as compared to other methods.

\section{Information literacy challenges}

Participants from different institutions highlighted the lack of support from the administration, as well as the top university management, which has led to the unstructured teaching of IL programme to students and these are done on a one-on-one basis or in groups.

Participants highlighted their experiences from their own institutions and indicated that there is no buy-in from the university stakeholders, which makes it even harder to implement IL in their institutions. Again, faculty librarians debated during the focus group discussion that institutional stakeholders are not forthcoming when it comes to library issues as they think IL is the library's responsibility. Baro, Seimode and Godfrey (2013) also discovered that a lack of cooperation and collaborative support from teaching staff concerning library services has become a threat to the library and its services.

\section{Limited facilities in the library}

Most academic libraries in underdeveloped countries have faced challenges such as a shortage of appropriate equipment. Both libraries that formally teach IL programmes and those that do not formally teach, indicated the challenges of inadequate facilities and infrastructure. IL is considered as both a theoretical and a practical programme; therefore, there is a need for proper infrastructure such as Internet facilities, adequate technological equipment, etc., to allow the quality delivery of IL programme. Some participants during the focus group discussion expressed the lack of appropriate equipment as a great challenge as they at times attend training sessions away from the library. Other participants specifically pointed out the issues of human resources, limited time, as well as limited budgets for buying IL equipment. Without the above-mentioned resources, IL was declared not to be successful.

\section{Poor infrastructure}

Infrastructure is one of the biggest challenges that impede the implementation and teaching of IL programmes as identified by Hepworth and Wema (2006). Faculty librarians indicated that it is quite disturbing to have improper infrastructure and inadequate resources in the library and this compromises the quality of library services. There is a need for well-furnished library computer labs, as well as good Internet facilities to carry out IL programme training effectively. Some participants responded positively, indicating the availability of library computer labs but added that they also need laptops and projectors because they have different campuses.

\section{Mitigating the challenges}

According to participant's responses, the consortium has taken further steps to involve the ZIMCHE into library service issues because a library is the heart of a university. Participants also highlighted that institutions should fight for collaboration with the university stakeholders, faculties and other relevant departments such as the Information and Communication Technologies Department. Above the highlighted challenges, it was noted that libraries do their best in advocating for IL but all in vain. Therefore, suggestions were made based on the need for the consortium to get involved on IL issues to assist institutions struggling with the formalisation of IL.

\section{Conclusion}

The study evaluated IL among selected academic libraries in Zimbabwe. The study established that IL practices existed in Zimbabwean academic libraries at different levels and formats. All the objectives of the study were addressed accordingly. All the participants were familiar with the term IL programme and understand its importance and benefits to the institutions of higher learning. They understand the importance of equipping students with such skills in the process of acquiring their degrees.

Research findings of the study revealed that both the university librarians and the faculty librarians had similar opinions on the important aspects that should be incorporated in the IL module. Although they differ in terminology, all the modules reviewed had similar topics which are theory of information retrieval, evaluation of information sources, referencing and citation, information search techniques, practical search from online databases and the online public access catalogue.

Lack of an IL policy, as understood by the library staff, discourages uniformity among the consortium members. Suggestions such as engaging the association and educational boards were made by the participants during the interview and this is supported by Tiemensma (2012:162), who highlighted that this leads to a smooth process of implementing and teaching IL. The issue of IL policy was one of the critical issues discussed. Recommendations were made and this 
would assist different Zimbabwean academic libraries, as well as library professionals.

After the study was carried out, researchers recommended the use of the IDEA and ADDIE models, which emphasise the analysis of the user needs to determine their abilities and inabilities, irrespectively. This may help to review the IL curriculum so as to align it with the needs of the students. This may as well augment and improve what is already available on the ground. Tompkins et al. (2014:140) highlight that the models provide a powerful guideline to librarians for creating IL modules, revising the existing IL modules and incorporating new technologies into library instructions.

There is a need for Zimbabwean institutions to produce its own toolkit that will guide the consortium members. As most institutions follow the ACRL framework, there is a need for Zimbabwean institutions to customise it, adopt and adapt to the Zimbabwean context. Thus, ACRL (2014) Framework for Information Literacy for Higher Education report also indicates that it laid a foundation that can be adopted by institutions in formulating their own IL policies.

\section{Acknowledgements Competing interests}

The authors declare that they have no financial or personal relationships which may have inappropriately influenced them in writing this article.

\section{Authors' contributions}

Both T.T. and J.C. conceptualised the study and then the first author T.T. did the research as part of her Master's Degree study. Both authors were involved in writing up the article. The second author edited and dealt with all comments from the reviewers and editorial board.

\section{References}

American Library Association, 2000, Presidential committee on information literacy, Final Report, American Library Association, Chicago, IL, viewed 27 August 2014 from http://www.ala.org/acrl/ilcomstan.html

Amunga, H.A., 2011, Information literacy in the 21st century universities: The Kenyan experience. International CALIBER, Goa University, Goa, India.

Association of College \& Research Libraries, 2000, Information literacy competency standards for higher education, viewed 14 May 2016, from http://www.ala.org/ acrl/standards/informationliteracycompetency

Association of College \& Research Libraries, 2014, Framework for information literacy for higher education, pp. 1-19, viewed 12 May 2016, from http://acrl.ala.org/ ilstandards/wp-content/uploads/2014/02/Framework-for-IL-for-HE-Draft-1Part-1.pdf

Baro, E. \& Fyneman, B., 2009, 'Information literacy among undergraduate students in Niger Delta University', The Electronic Library 27(4), 59-675.

Baro, E.E., 2011, 'A survey of information literacy education in library schools in Africa', Library Review 60(3), 202-217. https://doi.org/10.1108/002425311 1117263

Baro, E.E., Seimode, F.D. \& Godfrey, V.Z., 2013, 'Information literacy programmes in university libraries: A case study', Libri 63(4), 282-294. https://doi.org/10.1515/ libri-2013-0023

Berkman, R., 2016, 'ACRL's New Information Framework: Why now and what did it discover', 40(2), viewed 07 February 2017 from http://www.infotoday.com/ OnlineSearcher/Articles/Features/ACRLs-New-Information-Framework-Why-Nowand-What-Did-It-Discover-109503.shtml?PageNum=2

Chipeta, G.T., 2010, 'Information Literacy (IL) teaching and learning: A literature review', Inkanyiso: Journal of Humanities and Social Sciences 2(1), 21-31. https:// doi.org/10.4314/ijhss.v2i1.62118
Cobus, L., 2008, 'Integrating information literacy into the education of public health professionals: Roles for librarians and the library', Journal of the Medical Library Association: JMLA 96(1), 28. https://doi.org/10.3163/1536-5050.96.1.28

Creswell, J.W., 2009, Research design, Sage, London.

Goodman, V.D., 2009, Keeping the user in mind: Instructional design and the modern library, Chandos Publishing, Oxford.

Fitzpatrick, M.J. \& Meulemans, Y.N., 2011, 'Assessing an information literacy assignment and workshop using a quasi-experimental design', College Teaching 59(4), 142-149. https://doi.org/10.1080/87567555.2011.591452

Hart, G. \& Davids, M., 2010, 'Challenges for information literacy education at a university of technology', Innovation 41, 25-41.

Hennink, M., Hutter, I. \& Bailey, A., 2011, Qualitative research methods, Sage, London.

Hepworth, M. \& Wema, E., 2006, 'The design and implementation of an information literacy training course that integrated Information and Library Science conceptions of information literacy, educational theory and information behaviour research: A Tanzanian pilot study', Journal of Innovation in Teaching and Learning research: A Tanzanian pilot study', Journal of Innovat
in Information and Computer Sciences 5(1), 1-23.

Hodgens, C., Sendall, M.C. \& Evans, L., 2012, 'Post-graduate health promotion students assess their information literacy', Reference Services Review 40(3), 408-422.

Institute of Development Studies and Information Training and Outreach Centre for Africa, 2010, Strengthening information literacy interventions, creative approaches to teaching and learning, SCECSAL Pre-Conference Seminar Report, Gaborone, Botswana.

International Association of University Libraries, 2015, Information literacy policies and standards at IATUL member libraries, viewed 08 May 2018, from http://www. mediatum.ub.tum.de/doc/1286822

Kimani, H.N., 2014, 'Information literacy skills among incoming first-year undergraduate students at the Catholic University of Eastern Africa in Kenya', Masters Dissertation, University of South Africa, Pretoria.

Lau, J., 2006, Guidelines on information literacy for lifelong learning, IFLA, Veracruz.

Lawal, V., Underwood, P., Lwehabura, M. \& Stilwell, C., 2010, 'Information literacy for higher education institutions in Nigeria and Tanzania: Efforts and prospects for educational reform in teaching and learning', Innovation 41, 42-61.

Lwehabura, M.J. \& Stilwell, C., 2008, 'Information literacy in Tanzanian universities: Challenges and potential opportunities', Journal of Librarianship and Information Science 40(3), 179-191.

Mader, 2016, University of Alberta libraries: Information literacy, viewed 16 April 2017, from https://www.ualberta.ca/centre-for-teaching-and-learning/events/teachingevents-faculties/information-literacy

Maitaouthong, T., Tuamsuk, K. \& Tachamanee, Y., 2012, 'The roles of university libraries in supporting the integration of information literacy in the course instruction', Malaysian Journal of Library and Information Science 17(1), 51-64.

Moyo, M. \& Mavodza, J., 2015, 'A comparative study of information literacy provision at university libraries in South Africa and the United Arab Emirates: A literature review', Library Review 65(1/2), 93-107. https://doi.org/10.1108/LR-06-2015-0069

Mugwisi, T., 2015, 'Role of librarians in teaching information literacy in Zimbabwean and South African universities : A comparative study', Mousaion 33(1), 23-42.

Mullins, K., 2014, 'Good IDEA: Instructional design model for integrating information literacy', The Journal of Academic Librarianship 40(3-4), 339-349. https://doi. org/10.1016/j.acalib.2014.04.012

Mullins, K., 2016, 'IDEA model from theory to practice: Integrating information literacy in academic courses', The Journal of Academic Librarianship 42, 55-64.

Radia, P. \& Stapleton, P., 2008, 'Unconventional Internet genres and their impact on second language undergraduate students' writing process', The Internet and Higher Education 11(1), 9-17.

Roller, M.R. \& Lavrakas, P.J., 2015, Applied qualitative research design: A total quality framework approach, Guilford Publications, New York.

Rubin, A. \& Babbie, E., 2008, Research methods for social work, Wadsworth/Thomson Learning, Belmont, CA.

Saracevic, T., 2014, 'Information literacy in the United States: Contemporary transformations and controversies', Communications in Computer and Information transformations and
Science 492, 19-30.

Summey, T.P. \& Valenti, S., 2013, 'But we don't have an instructional designer: Designing online library instruction using ISD techniques', Journal of Library \& Information Services in Distance Learning 7, 169-182. https://doi.org/10.1080/15 33290X.2012.705630

The African Journal, viewed 16 September 2013, from https://www.herald.co.zw/ time/to-go-beyond-literacy/htm

The Society for the Advancement of Library and Information Science (SALIS), in collaboration with UNESCO and BS Abdur Rahman Crescent Engineering College, 2009, 'Background Document of the Expert Meeting', International conference on knowledge networking in ICT Era, UNESCO 2009, Chennai, India, January 22-24, 2009, n.p

Thomas, D.R., 2011, 'A general inductive approach for analyzing qualitative evaluation data', American Journal of Evaluation 27(2), 237-246.

Tiemensma, L., 2012, 'Information literacy education in higher education institutions in South Africa', The road to information literacy: Librarians as facilitators of learning, Berlin, de Gruyter 157, 155-168.

Tompkins, G., Campbell, R., Green, D. \& Smith, C., 2014, Literacy for the 21st century, Pearson, Melbourne, Australia.

Yin, R.K., 2012, Applications of case study research, Sage, Thousand Oaks, CA. 